\title{
Kolorektal karsinogenez ve metabolik sendrom ilișkisi
}

\section{The relation between colorectal carcinogenesis and metabolic syndrome \\ Elife Erarslan*, İlhami Yüksel, Serap Haznedaroğlu}

Gastroentereoloji Bölümü (Dr. E. Erarslan, Dr. İ. Yüksel, Dr. S. Haznedaroğlu), Etlik İhtisas Eğitim ve Araştırma Hastanesi, TR-06010 Ankara

\begin{abstract}
Özet
Metabolik sendrom obezite, dislipidemi, hiperglisemi ve hipertansiyon gibi hastalıkların toplamından oluşur. Metabolik sendrom bileşenlerinin çoğu tümör gelişimi ile bağlantılıdır. Metabolik sendrom ve visseral obezitenin genel populasyonda sıklık ve yaygınlığı giderek artmaktadır. Obezite son zamanlarda kanserlerin çoğunda mortalite ile bağlantılıdır. Kolorektal kanser önemli bir halk sağlı̆̆ problemidir. Son raporlar metabolik sendromlu bireylerde kolon veya rektum kanseri riskinin yüksek olduğunu göstermiştir. Metabolik sendrom ve kolorektal kanser arasındaki bağlantının patofizyolojik mekanizması çoğunlukla abdominal obezite ve insülin direnci ile ilişkilidir. Beslenme, egzersiz ve stresi azaltmayı kapsayan multidisipliner bir yaklaşım insülin direncini sınırlamada ve kanser sonuçlarını iyileştirmede çok önemli bir firsat olabilir.
\end{abstract}

Anahtar sözcükler: Metabolik sendrom, kanser, insülin direnci, obezite

\begin{abstract}
Metabolic syndrome consists of a cluster of diseases including obesity, dyslipidemia, hyperglycemia and hypertension. Most of the components of metabolic syndrome have been associated with the development of neoplasm. The metabolic syndrome and visceral obesity have an increasing prevalence and incidence in the general population. Obesity has recently been linked to mortality in the majority of cancers. Colorectal cancer is an important public health problem. Recent reports in individuals with metabolic syndrome showed a high risk of colon or rectal cancer. The pathophysiological mechanism that links metabolic syndrome and colorectal cancer is mostly related to abdominal obesity and insulin resistance. A multidisciplinary approach involving nutrition, exercise, and stress reduction may be an opportunity to limit the insulin-resistant state and improve cancer outcomes.
\end{abstract}

Keywords: Metabolic syndrome, cancer, insulin resistance, obesity

Geliş tarihi/Received: 03 Şubat 2011; Kabul tarihi/Accepted: 11 Nisan 2011

\section{*İletişim adresi:}

Dr. Elife Erarslan, Gastroenteroloji Bölümü, Etlik İhtisas Eğitim ve Araştırma Hastanesi, TR06010 Ankara. E-posta: elifeerarslan@gmail.com

\section{Giriş}

Kolorektal kanserler Amerika'da en yaygın görülen üçüncü malignitedir. Her yıl dünya çapında tanı konan bir milyon yeni vaka ve yarım milyona yakın ölüm oranı ile önemli bir sağlık sorunudur [1]. Hem erkek hem de kadınlarda obezite ile KRK arasında ilişki olduğu gösterilmiştir. Kolorektal kanser etyolojisinde çevresel ve genetik faktörlerin etkisi vardır [2]. Abdominal obezite için Ulusal Kolesterol Eğitim Programı Erişkin Tedavi Paneli'nin [The National Cholesterol Education Program Adult Treatment Panel (NCEP-ATPIII)] önerdiği bel çevresi (BÇ) sınır değerleri erkeklerde $\geq 102 \mathrm{~cm}$, kadınlarda $\geq 88 \mathrm{~cm}$ ve Uluslararası Diyabet Federasyonu (IDF) kriterlerine göre erkeklerde $\geq 94 \mathrm{~cm}$ ve kadınlarda $\geq 80 \mathrm{~cm}$ 'dir [3]. Obezite ve metabolik sendrom (MS) prevalans1 
gelişen ve gelişmekte olan ülkelerde artmaktadır. Tüm dünyada olduğu gibi Türkiye'de de MS'un görülme sıklığının arttığı bildirilmiştir. Türkiye'de yapılan MS prevalans çalışmasında (METSAR) MS prevalansı kadınlarda \%39,6 ve erkeklerde \%28'dir. 70 yaş üzerinde ise prevalans kadınlarda $\% 70$, erkeklerde $\% 49$ bulunmuştur [4]. MS, santral obezite, bozulmuş glukoz tolerans1, HT, hipertrigliseridemi, yüksek yoğunluklu lipoprotein kolesterol (HDL-K) düşüklüğü ile karekterizedir $[1,3,5]$. İnsülin direnci, dolaşımda yüksek insülin düzeyi ile karakterize prediyabetik bir durumdur. Obezite, İD, hiperinsülinemi ve kolon karsinogenezinin etyolojisinde rol oynar $[2,5,6]$. Hiperinsülinemi ve metabolik bozukluklar, kolorektal kanser, meme kanseri, prostat kanseri, ve diğer birçok kanser türünde risk artışına neden olur $[5,7,8]$. Bu derlemede MS ile KRK ilişkisi epidemiyolojik veriler ve patofizyolojik mekanizmalar eşliğinde incelenecektir.

\section{Metabolik sendrom; tanım}

Metabolik sendrom, NCEP-ATP III ve Uluslararası Diyabet Federasyonu (IDF) kriterlerine dayanarak tanımlanmış ve Tablo1'de özetlenmiştir. NCEP-ATP III kriterlerine göre beş kriterden üç veya daha fazlasının olması ve IDF kriterlerine göre santral obeziteye Tablo1'de belirtilen dört metabolik risk faktöründen ikisinin eklenmesi metabolik sendrom tanısı için yeterlidir [3].

Tablo 1. Ulusal Kolesterol Eğitim Programı Erişkin Tedavi Paneli (the National Cholesterol Education Program Adult Treatment Panel-NCEP-ATP III) ve Uluslararasi Diyabet Federasyonu (IDF) Kriterlerine Göre Tanımlanmış Metabolik Sendrom [3].

\begin{tabular}{ll}
\hline \multicolumn{2}{c}{ Metabolik sendrom tanımlarının karşılaştırılması } \\
\hline \multicolumn{1}{c}{ ATP III 2001 } & \multicolumn{1}{c}{ IDF 2005 } \\
\hline Beş kriterden üç veya daha & Santral obeziteye dört metabolik risk faktöründen ikisini \\
fazlası & ekleyerek \\
Santral obezite: Bel çevresi & Santral obezite: Bel çevresi \\
Kadın $\geq 88 \mathrm{~cm}$, erkek $\geq 102 \mathrm{~cm}$ & kadın $\geq 80 \mathrm{~cm}$, erkek $\geq 94$ \\
Trigliserid $>150 \mathrm{mg} / \mathrm{dL}$ & Trigliserid $>150 \mathrm{mg} / \mathrm{dL}$ \\
Düşük HDL kolesterol: & Düşük HDL kolesterol: \\
$<40 \mathrm{mg} / \mathrm{dL}($ erkek) & $<40 \mathrm{mg} / \mathrm{dL}($ erkek) \\
$<50 \mathrm{mg} / \mathrm{dL}(\mathrm{kad} ı n)$ & $<50 \mathrm{mg} / \mathrm{dL}(\mathrm{kad} ı n)$ \\
Kan basıncı $\geq 130 / 85 \mathrm{mmHg}$ & Kan basıncı $\geq 130 / 85 \mathrm{mmHg}$ \\
Açlık kan şekeri $100 \mathrm{mg} / \mathrm{dL}$ & Açlık kan şekeri $100 \mathrm{mg} / \mathrm{dL}$ \\
\hline
\end{tabular}

\section{Epidemiyoloji}

Son yıllarda yapılan çalışmalarda KRK insidansı ve özellikle MS bileşenleri [VKİ, BÇ, lipid düzeyleri, plazma glukoz ve glikozile hemoglobin A1c (HbAlc)] arasındaki ilişki araştırılmıştır. 1978-87 yılları arasında İtalya'da 21,311 erkek ve 15,991 kadın olgu ile yapılan Risk Faktörleri ve Yaşam Beklentisi çalışmasında, epidemiyolojik dokuz çalışmanın birleştirilmiş verilerine göre düşük HDL ve yüksek trigliserid düzeyi, HT ve plazma glukoz düzeyleri MS'un bileşenleri olarak belirlenmiştir [1]. Yakın zamanda yayınlanan METSAR çalışmasının analiz sonuçlarına göre ülkemizde abdominal obezite (BÇ, erkeklerde $\geq 102 \mathrm{~cm}$, kadınlarda $\geq 88 \mathrm{~cm}$ ) prevalansı \%36,2, (kadınlarda $\% 54,8$, erkeklerde \%17,2) olarak belirlenmiştir. Bel çevresi sınırını erkeklerde $\geq 94 \mathrm{~cm}$, kadınlarda $\geq 80 \mathrm{~cm}$ kabul eden ve MS tanısı için abdominal obeziteyi şart koşan IDF kıstasları uygulandığında ülkemizde MS prevalansı \%42,6 (kadınlarda \%51,1, erkeklerde $\% 33,9)$ olarak belirlenmiştir. Saptanan yüksek prevalans değerleri abdominal obezite tanımıyla yakından ilişkilidir [9]. Onat ve arkadaşları'nın yeni gelişen tip 2 diyabet ile koroner kalp hastalığını öngörmede metabolik sendromun rolünü araştırdığı çalışma özellikle abdominal obezite tanımının Türk toplumuna uyarlanması açısından değerlidir. Türk toplumu için BÇ değerinin IDF'e benzer şekilde erkeklerde $\geq 94 \mathrm{~cm}$ ve ATP III'ün önerdiği gibi kadınlarda $\geq 88 \mathrm{~cm}$ olarak kalmasını benimsemişlerdir [10]. Garow ve arkadaşlarının 2002-2003 yıllar arasında yaptığı ve 58,000 olgunun katıldığı Ulusal 
Sağlık Görüşme Anketi çalışmasında MS tanısı konan 1200 olgunun 350'sinde KRK tespit edilmiştir. Metabolik sendromlu olguların yaş, ırk, cinsiyet, obezite, sigara ve alkol açısından kontrolünden sonra kolon veya rektum kanseri için \%75 risk artışı olduğu belirlenmiştir [11]. Plazma glukoz düzeyleri ve KRK insidansı arasındaki ilişki Avrupa Prospektif Kanser ve Beslenme İncelenmesi çalışmasında (EPIC) prospektif bir analiz ile özetlenmiştir [12]. Yaşları 45 ve 79 arasında değişen 9605 katılımeı ile yapılan bir çalışmada, 67 olguda KRK tanısı konmuştur. Yüksek HbA1c düzeyleri ve KRK arasındaki artmış risk aynı zamanda Clue II kohort çalışmasında da tespit edilmiştir [13]. Kolon kanserli 984 olgu ile yapılan son EPIC çalışmasında VKİ ve KRK arasındaki ilişki incelenmiştir. Vücut kitle indeksinin düşük ve yüksek dilimleri arasındaki erkeklerin \%55'inde kolon kanseri riskinde artış olduğu fakat kadınlarda anlamlı ilişki olmadığı gözlenmiştir [14]. Bazı yeni çalışmalar adenomun kolon kanseri ile ilişkisinde VKİ'ne ek olarak yă̆ dağılımının antropometrik ölçümlerininin de dikkate alınmasını öngörmektedir. Bu çalışmaların çoğunda $\mathrm{BÇ}$ veya bel kalça oranı (BKO) ve kolon kanseri riski ilişkisi, VKİ ve kanser arasındaki ilişkiden daha güçlü bulunmuştur [15]. Moore ve arkadaşlarının [15] yaptığı retrospektif bir çalışmada 7556 vakadan 306'sında rastlantısal olarak KRK bulunmuş ve $\mathrm{BÇ}>99 \mathrm{~cm}$ olan kadınlarda ve $\mathrm{BÇ}>101 \mathrm{~cm}$ olan erkeklerde KRK riskinin 2 kat arttığ1 ve bu riskin $\mathrm{BÇ}$ artış1 ile lineer olarak arttı̆̆ gösterilmiştir. Epidemiyolojik kanttlar obezite ile kanserlerden ölüm riskinde artma arasında ilişki olduğunu göstermiştir [1, 5, 7]. Türkiye'de 40 yaş ve üzeri kolorektal adenomlu ve kanserli 54 hasta ile yapılan çalışmada kolorektal karsinogenez ile VYA ve serum adiponektin ilişkisi değerlendirilmiştir. Çalışmada VYA düzeyinin KRK'li hastalarla kontrol vakaları arasında farklı olmadığı ve adiponektin düzeyinin VYA ile korele olmadığı tespit edilmiştir [16]. Son zamanlarda, çeşitli çalışmalarda hiperinsülinemi ve/veya diyabetin kolorektal karsinogenezde önemli bir rol oynadığı gösterilmiştir. İnsülin direnci KRK'de ölüm riski artışı ile bağlantılıdır. İnsülin direnci ve/veya hiperinsülinemi MS gelişmesine önemli katkı yaptığı için MS ve KRK arasında da benzer bir ilişki var olabilir [1, 5, 7, 17]. Bir başka çalışmada MS komponentleri ile KRK riskinin anlamlı olarak arttığı gösterilmiştir [1]. Hem erkeklerde hem de kadınlarda obezite ile kolon kanseri arasında ilişki olduğu gösterilmiştir [2, 9, 12].

\section{Obezite ve kolorektal kanser}

Kolorektal kanserler, kanserle ilişkili ölümlerin yaklaşı $\% 10$ 'dan sorumludur. Obezitenin kolon kanseri üzerine olumsuz etkisinin mekanizmalarından birisi obez kişilerde insülin ya da insülin ile ilgili büyüme faktörlerinin tümör gelişimini büyük oranda teşvik ediyor olmasıdır [7, 18, 19]. Yapılan çalışmalarda abdominal yağlanmanın iki ölçüsü olan bel çevresi veya BKO ve kolon kanseri ilişkisi, VKİ ile kanser arasındaki ilişkiden daha güçlü bulunmuştur $[14,15,18]$. Vücut kitle indeksi yüksek olan erkeklerde kolon kanseri riski artmış görülürken kadınlarda bu ilişki daha zayıf bulunmuştur. Erkeklerde artmış VKİ abdominal yağlanma ile ilişki bulunmuştur [6, 20, 21].

\section{Metabolik sendrom ve kolorektal kanser arasındaki fizyopatolojik ilişkiler}

\section{İnsülin direnci ve insülin büyüme faktörü bağlayıcı protein}

Metabolik sendromun en önemli mekanizmasının İD olduğu öne sürülmüştür. İnsülin normal mukozada apoptozu azaltarak kolorektal adenomdan kanser gelişme zincirini uyarabilir $[1,5,8]$. Kolon mukozasındaki normal epitel hücrelerinin yanında kanser hücrelerinde de insülin ve IGF-1 reseptörlerinin olduğu gösterilmiştir. İnsülin bu hücrelerin büyümesini doğrudan ya da dolaylı olarak İnsülin benzeri büyüme faktörü-1 (IGF-1) yoluyla etkileyerek in vitro ve deneysel modellerde mitojenik etki gösterir [1, 7, $8,18]$. Hiperinsülinemi, dolaşımdaki IGF bağlanan protein-1'in (IGFBP-1) düzeylerini azaltıp, serbest IGF-1 düzeylerinin artmasına yol açarak KRK riskini artırıyor olabilir. Hiperinsülinemi IGFBP-1, IGFBP-2 ve IGFBP-3 üretimini inhibe edebilir [7, 8, 18]. IGF-1 tek zincirli 70 aa'ten oluşan bir polipeptiddir. IGF-1 fizyolojik olarak, büyüme hormonunun $(\mathrm{GH})$ etkisinden sorumlu major mediatördür. IGF-1 önemli bir mitojendir ve hücre proliferasyonu ve apoptoz üzerinde parakrin, otokrin ve endokrin etkileri vardır [7, 
18]. Buna ek olarak, IGF-1 kanser gelişmesini destekleyen bir anjiogenik faktör olan vasküler endotelyal büyüme faktörünün (VEGF) üretimini artırır. IGF-1 içinde kolorektal kanserinde bulunduğu birçok kanser riskiyle ilişkili bulunmuştur $[1,7,18]$.

\section{Adipokinler ve inflamatuar sitokinler}

Yağ dokusu hormon, sitokin ve diğer sinyal proteinlerinin salg1 ve sentezinden sorumlu topluca adipokinler olarak adlandırılan karmaşık bir endokrin organdır. Adipokinler, iştah ve enerji dengesi, inflamasyon, insülin direnci/hassasiyeti, anjiyogenez, lipid metabolizması, hücre çoğalması ve ateroskleroz gibi süreçlerde rol oynayan sinyalizasyon moleküllerinin farklı bir grubudur $[1,2]$. Bu işlevlerin çoğu ya MS veya kanser ile ilgili olup, bu iki patoloji arasında bir bağlantı olarak sağlayabilir. Adiponektin, leptin ve TNF$\alpha$, IL-6, IL-8, IL-10 ve IL-1-reseptör agonisti gibi sitokinler topluca adipositokinler olarak adlandırılabilir [1, 16, 22-24]. Adiponektin, adipoz doku tarafindan sentezlenen ve 30 kDa (GBP28, adipoQ ya da ACRP30 ) ağırlığında C1q ilişkili kollajen benzeri bir plazma proteinidir ve en çok salınan adipositokindir. Ağırlıklı olarak visseral yağ dokusunda salgılanır. Adiponektinin düşük molekül ağırlıklı ve yüksek molekül ağırlıklı iki formunun olduğu ve yüksek molekül ağırlıklı adiponektinin kanser riskiyle daha yakın ilişkili olduğu tespit edilmiştir [2, 16, 19]. Adiponektin düzeyi VKİ ile ters ilişkilidir ve insülin duyarlaştırıcı, antianjiogenik, antiinflamatuar, apoptozis ve inflamasyonun düzenlenmesine de katkıda bulunan bir hormondur [2, 19, 22]. Makrofajdan TNF- $\alpha$ ve benzeri sitokin üretimini baskılayarak tümör nekrozis faktör- $\alpha$ (TNF- $\alpha$ ) tarafindan indüklenen inflamatuvar hücre göçünü inhibe eder. Hayvanlarda tümör büyümesini engelleyebilir. Düzeyleri mide kanseri ile negatif korelasyon gösterir. Bu protein insülin uyarıcısı olmamakla birlikte iskelet kasındaki serbest yağ asitlerinin beta oksidasyonunu arttırarak insülin etkisinden koruma sağlar. Adiponektin düzeyinin tip 2 diyabet, obezite ve dislipidemi gibi İD olan durumlarda azaldığ 1 görülmüştür $[12,19,22]$. Wei ve arkadaşlarının yaptı̆̆ prospektif bir çalışmada plazma ADP düzeyi erkeklerde KRK riskiyle ters ilişkili olarak bulunmuştur. Aynı çalışmada plazma ADP düzeyindeki azalma kolorektal adenom gelişimiyle ilişkili bulunmuştur. VKİ artışı ile ADP azalmasının kanser riskini $\geq 6$ kat artırdığı bildirilmektedir [22].

\section{Leptin}

Leptin >\%95 adipositler tarafından salınan $16 \mathrm{kDa}$ ağırlığında bir glikoproteindir. Son zamanlarda leptinin obezitedeki rolünden çok inflamatuar cevap, insülin uyarımı ve karsinogenez ile ilişkisi üzerinde durulmaktadır. Leptin özellikle sitokin sinyal 1 ve 3 baskılayıcıları üzerinden insülini uyarıcı etki yapar. Kolon kanserinin doğrudan leptin ile bağlantısını gösteren veriler sınırlı olsa da, yüksek serum leptin düzeyi ile kolon ve KRK riski bazı çalışmalarda gösterilmiştir [1]. Norveç kohort çalışmasından elde edilen verilere göre VKİ'den bağımsız olarak yüksek leptin düzeyli insanlar arasında kolon kanseri riski yaklaşık 3 kat artmıştır [1]. Japonya'da yapılan bir vaka-kontrol çalışmasında kadınlarda leptin konsantrasyonu ve KRK arasındaki ilişki değerlendirilmiş ve leptinin kadınlarda KRK riskini VKİ'den bağımsız olarak önemli ölçüde artırdığı gösterilmiştir [23].

\section{Inflamatuvar sitokinler ve kolorektal kanser}

Elde edilen kantlar sistemik inflamasyonun KRK için makul bir mekanizma olabileceğini düşündürmektedir. Çalışmalar interlökin (IL)-6, IL-8 ve IL-10 gibi inflamasyonla ilişkili genlerdeki genetik varyasyonların, kolorektal adenom ve KRK'a yatkınlık ile ilişkili olduğunu göstermiştir. IL-6'nın hücre büyümesini uyararak ve apoptozisi inhibe ederek parakrin ve otokrin bir mekanizma ile tümör oluşumunu artırdığı görülmektedir. Ayrıca IL-6 düzeylerinin hastalık durumunu yansıttığı ve yaygın metastatik hastalık ile ilişkili olduğu belirlenmiştir [1]. TNF- $\alpha$, NO üretimini artıran ve diğer inflamatuar sitokinleri uyaran NF-kB' y1 aktive eder. IL-6, TNF- $\alpha$, ve C-reaktif proteinin (CRP) yüksek düzeyleri ile karsinogenez gelişmesi arasında ilişki olduğunu gösteren çok sayıda çalışma vardır. Ayrıca, Yunanistan'da yapılmış bir çalışmada, serum 
IL-6, TNF- $\alpha$ ve CRP düzeyi yüksekliği ile tümör büyüklüğü arasında da ilişki olduğu gösterilmiştir[24].

\section{Ppar- $\gamma$}

PPAR- $\gamma$, adipojenik farklılaşma ve glikoz dengesinde önemli bir düzenleyici olan transkripsiyon faktörüdür. PPAR- $\gamma$ ligandların son zamanlarda kanser hücre dizilerinde çoğalma ve farklılaşmayı etkilediği gösterilmiştir. PPAR- $\gamma$ ve KRK arasındaki ilişkiyi ortaya koyan çok sayıda çalışma mevcuttur. Yeni yapılan bir çalışmada kolon kanserli 86 olgunun 48'inde (\%56) PPAR- $\gamma$ pozitif immün boyanma görülmüştür [25].

Sonuç olarak çok sayıda epidemiyolojik çalışmada obezite, dislipidemi ve bozulmuş glukoz toleransı gibi metabolik sendrom komponentlerinin kolorektal karsinogenez gelişimi ile ilişkili olduğu belirlenmiştir. Metabolik sendrom bileşenlerinin farklı patofizyolojik yollar aracılığı ile kolon kanseri gelişimine aditif etki yaptığı anlaşılmıştır. Yüksek kalorili diyet ile beslenen şişman ve aşırı kilolu bireylerin yaygın olduğu sanayileşmiş toplumların ortak özellikleri hiperinsülinemi ve İD’nin sık olmasıdır. Metabolik sendrom ve bileşenlerinin kolorektal karsinogenez ile ilişkisinin patofizyolojik mekanizmalarını anlamak hem korunma hem de tedavide yeni stratejilerin gelişmesinde çok büyük önem taşır. Metabolik sendrom bileşenlerinin bir ya da iki komponentinin kontrol edilmesi bile, daha uzun, sağlıklı ve kansersiz bir hayatla sonuçlanabilir.

\section{Kaynaklar}

1. Pais R, Silaghi H, Silaghi AC, Rusu ML, Dumitrascu DL. Metabolic syndrome and risk of subsequent colorectal cancer. World J Gastroenterol 2009; 15: 5141-8.

2. Gönüllü G, Kahraman H, Bedir A, Bektas A, Yücel İ. Association between adiponectin, resistin, insulin resistance, and colorectal tumors. Int $\mathbf{J}$ Colorectal Dis 2010; 25: 205-12.

3. Grundy SM, Cleeman JI, Daniels SR, Donato KA, Eckel RH, Franklin BA, Gordon DJ, Krauss RM, Savage PJ, Smith SC Jr, Spertus JA, Costa F; Diagnosis and management of the metabolic syndrome: an American Heart Association/National Heart, Lung, and Blood Institute Scientific Statement. Circulation 2005; 112: 2735-52.

4. Çengel A. Kadınlarda kardiyovasküler risk faktörleri. Türk Kardiyol Dern Arş 2010; 1: 17-24.

5. Lee GE, Park HS, Yun KE, Jun SH, Kim HK, Cho Sİ, Kim JH. Association between BMI and metabolic syndrome and adenomatous colonic polyps in Korean men. Obesity 2008; 16: 1434-9.

6. Trevisan M, Liu J, Muti P, Misciagna G, Menotti A, Fucci F; Risk Factors and Life Expectancy Research Group. Markers of insulin resistance and colorectal cancer mortality. Cancer Epidemiol Biomarkers Prev 2001; 10: 937-41.

7. Boyd DB. Insulin and cancer. Integr Cancer Ther 2003; 2: 315-29.

8. Giovannucci E. Insulin, insulin-like growth factors and colon cancer: a review of the evidence. J Nutr 2001; 131: 3109-20.

9. Onat A, Hergenç G, Can G. Prospective validation in identical Turkish cohort of two metabolic syndrome definitions for predicting cardiometabolic risk and selection of most appropriate definition. Anadolu Kardiyol Derg 2007; 7: 29-34.

10. Kozan O, Oğuz A, Abacı A, Erol C, Öngen Z, Temizhan A, Çelik S. Prevalence of the metabolic syndrome among Turkish adults. Eur J Clin Nutr 2007; 61: 54853.

11. Garow D. Metabolic syndrome is a risk factor for colorectal cancer in the United States. American College of Gastroenterology 2008; Annual Scientific Meeting.

12. Khaw KT, Wareham N, Bingham S, Luben R, Welch A, Day N. Preliminary communication: glycated hemoglobin, diabetes, and incident colorectal cancer in men and women: a prospective analysis from the European prospective investigation into cancer-Norfolk study. Cancer Epidemiol Biomarkers Prev 
2004; 13: 915-9.

13. Saydah SH, Platz EA, Rifai N, Pollak MN, Brancati FL, Helzlsouer KJ. Association of markers of insulin and glucose control with subsequent colorectal cancer risk. Cancer Epidemiol Biomarkers Prev 2003; 12: 412-8.

14. Pischon T, Lahmann PH, Boeing $\mathrm{H}$, Friedenreich $\mathrm{C}$, Norat $\mathrm{T}$, Tjønneland A, Halkjaer J, Overvad K, Clavel-Chapelon F, Boutron-Ruault MC, Guernec G, Bergmann MM, Linseisen J, Becker N, Trichopoulou A, Trichopoulos D, Sieri S, Palli D, Tumino R, Vineis P, Panico S, Peeters PH, Bueno-de-Mesquita HB, Boshuizen HC, Van Guelpen B, Palmqvist R, Berglund G, Gonzalez CA, Dorronsoro M, Barricarte A, Navarro C, Martinez C, Quirós JR, Roddam A, Allen N, Bingham S, Khaw KT, Ferrari P, Kaaks R, Slimani N, Riboli E. Body size and risk of colon and rectal cancer in the European Prospective Investigation Into Cancer and Nutrition (EPIC). J Natl Cancer Inst 2006; 98: 920-31.

15. Moore LL, Bradlee ML, Singer MR, Splansky GL, Proctor MH, Ellison RC, Kreger BE. BMI and waist circumference as predictors of lifetime colon cancer risk in Framingham Study adults. Int J Obes Relat Metab Disord 2004; 28: 55967.

16. Erarslan E, Turkay C, Koktener A, Koca C, Uz B, Bavbek N. Association of visceral fat accumulation and adiponectin levels with colorectal neoplasia. Dig Dis Sci 2009; 54: 862-8.

17. Jee SH, Ohrr H, Sull JW, Yun JE, Ji M, Samet JM. Fasting serum glucose level and cancer risk in Korean men and women. JAMA 2005; 293: 194-202.

18. Komninou D, Ayonote A, Richie JP Jr, Rigas B. Insulin resistance and its contribution to colon carcinogenesis. Exp Biol Med (Maywood) 2003; 228: 396405.

19. Ealey KN, Archer MC. Elevated circulating adiponectin and elevated insulin sensitivity in adiponectin transgenic mice are not associated with reduced susceptibility to colon carcinogenesis. Int J Cancer 2009; 124: 2226-30.

20. Caan BJ, Coates AO, Slattery ML, Potter JD, Quesenberry CP Jr, Edwards SM. Body size and the risk of colon cancer in a large case-control study. Int J Relat Metab Disord 1998; 22: 178-84.

21. Murphy TK, Calle EE, Rodriguez C, Kahn HS, Thun MJ. Body mass index and colon cancer mortality in a large prospective study. American Journal of Epidemiology 2000; 152: 847-54.

22. Wei EK, Giovannucci E, Fuchs CS, Willett WC, Mantzoros CS. Low plasma adiponectin levels and risk of colorectal cancer in men: A prospective study. J Natl Cancer İnst 2005; 97: 1688-94.

23. Tamakoshi K, Toyoshima H, Wakai K, Kojima M, Suzuki K, Watanabe Y, Hayakawa N, Yatsuya H, Kondo T, Tokudome S, Hashimoto S, Suzuki S, Kawado M, Ozasa K, Ito Y, Tamakoshi A. Leptin is associated with an increased female colorectal cancer risk: a nested case-control study in Japan. Oncology 2005; 68: 454-61.

24. Nikiteas NI, Tzanakis N, Gazouli M, Rallis G, Daniilidis K, Theodoropoulos G, Kostakis A, Peros G. Serum IL-6, TNFalpha and CRP levels in Greek colorectal cancer patients: prognostic implications. World J Gastroenterol 2005; 11: 163943.

25. Fajas L, Debril MB, Auwerx J. Peroxisome proliferator-activated receptorgamma: from adipogenesis to carcinogenesis. J Mol Endocrinol 2001; 27: 1-9. 